\title{
Racial and ethnic disparities in COVID-19 vaccinations in the United States during the booster rollout.
}

Jeremy Samuel Faust, MD, MS, corresponding author*

Department of Emergency Medicine, Brigham and Women's Hospital, Boston, Massachusetts.

Benjamin Renton, BA, Ariadne Laboratories, Boston, Massachusetts

Utibe R. Essien, MD, MPH, Division of General Internal Medicine, University of Pittsburgh

School of Medicine, Pittsburgh, Pennsylvania

Céline R. Gounder, MD, ScM, NYU Grossman School of Medicine and Bellevue Hospital Center

Zhenqiu Lin, PhD, Yale School of Medicine, Center for Outcomes Research and Evaluation,

New Haven, CT

Harlan M. Krumholz MD, SM

Yale University School of Medicine, Center for Outcomes Research and Evaluation

New Haven, CT

Word count: 650

1 figure, 1 table, 6 references

*jsfaust@gmail.com

\section{Abstract}


Background: We sought to quantify whether there were statistically significant disparities along race and ethnicity lines during the early rollout of Covid-19 vaccine booster doses in the United States. We also studied whether such disparities replicated or widened disparities that had already been observed during the initial series rollout as of 2 months earlier (Janssen) or 6 months earlier (Pfizer-BioNTech or Moderna), which comprised the booster-eligible population.

Methods: This cross-sectional study of US adults (ages $\geq 18$ years) used public data from US Centers for Disease Control and Prevention. The observed shares of vaccine doses for each race and ethnicity were compared to the expected shares, predicted based upon the compositions of the booster-eligible and initial series-eligible populations.

Results: As of November 16, 2021, 123.5 million US adults were eligible for a booster dose of either the Pfizer-BioNTech, Moderna, or Janssen vaccines. Of these, 21.7 million had received a booster dose, among whom race and ethnicity information was available for 18.8 million booster recipients.

A statistically significant higher share of Non-Hispanic White and Non-Hispanic Multiple/Other race individuals had received a booster vaccination than projected based on the composition of the booster-eligible population. A statistically significant lower share of Hispanic, NonHispanic American Indian/Alaskan Native, Non-Hispanic Asian, Non-Hispanic Black, and NonHispanic Native Hawaiian/Other Pacific Islander individuals had received a booster vaccination than expected based on the booster-eligible population. A secondary analysis of the boostereligible population found that some of these disparities had already occurred at the time of the initial series. However, the booster campaign widened all of those disparities and added new disparities for Non-Hispanic American Indian/Alaskan Native and Non-Hispanic Native Hawaiian/Other Pacific Islander individuals.

Conclusion: Disparities in Covid-19 vaccine administration on race and ethnicity lines occurred during the initial series rollout in the US. However, these disparities were not merely replicated but widened by the early booster rollout.

\section{Introduction}


US Centers for Disease Control and Prevention (CDC) data reveal marked disparities in Coronavirus disease-2019 (COVID-19) vaccine administration by race and ethnicity. ${ }^{1,2}$ We sought to quantify these disparities and determine whether they widened during the booster rollout.

\section{Methods}

Using CDC publicly available (with the exception of Texas) vaccination and population data, ${ }^{3 / 4}$ race and ethnicity data were categorized into 7 groups: Hispanic/Latino and Non-Hispanic (NH) American Indian/Alaskan Native (Al/AN), Asian, Black, Native Hawaiian/other Pacific Islander (NHOPI), White, and Multiple/Other race. For each group, initial vaccination administration (by May 16, 2021 for the Pfizer-BioNTech and Moderna vaccines, and September 16, 2021 for the Janssen vaccine) was compared by race and ethnicity with each group's share of the vaccineeligible adult population (US adults ages $\geq 18$ ). Then, the share of booster doses administered (by November 16,2021 ) to recipients of known race and ethnicity was compared with each group's share of the booster-eligible population (US adults ages $\geq 18$ who had been vaccinated 6 months earlier if receiving Pfizer-BioNTech or Moderna vaccines, or 2 months earlier if receiving Janssen vaccines). A statistically significant disparity was defined as any observed share of vaccine doses falling below the $95 \% \mathrm{Cl}$ for that group's projected share, based on the composition of the eligible populations. Analyses were performed in SAS 9.4.

\section{Results}


As of November 16, 2021, there were 123.5 million booster-eligible US adults, among whom $27.1 \mathrm{~m}(21.9 \%)$ had received a booster. Race and ethnicity information was available for $18.8 \mathrm{~m}$ (69.4\%) booster recipients. A statistically significant higher share of $\mathrm{NH}-$ White and $\mathrm{NH}$ Multiple/Other race individuals had received a booster vaccination than expected based on the composition of the booster-eligible population (Figure, Table). A statistically significant lower share of Hispanic, NH-Al/AN, NH-Asian, NH-Black, and NH-NHOPI individuals had received a booster vaccination than expected based on the booster-eligible population (Figure,Table).

To assess whether disparities in booster administration replicated or widened ones present during the initial series rollout, an analysis of the initial series was conducted. As of November 16, 2021, there were $123.5 \mathrm{~m}$ booster-eligible US adults (ie. had completed the initial series either 2 months (Janssen) or 6 months prior (Pfizer-BioNTech, Moderna)); race and ethnicity information was available for $85.8 \mathrm{~m}(69.5 \%)$. Given the composition of the vaccine-eligible population, a statistically significantly higher share of $\mathrm{NH}-$ White, NH-Al/AN, NH-NHOPI, and $\mathrm{NH}$-Multiple/Other individuals had completed the initial series and were booster-eligible than expected (Figure, Table); a statistically significantly lower share of Hispanic, $\mathrm{NH}$-Asian, and $\mathrm{NH}$ Black individuals had completed the initial series and were booster-eligible than expected (Figure Table).

\section{Discussion}


These data indicate that disparities in Covid-19 vaccine administration on race and ethnicity lines during the initial series in the US were widened by the early booster rollout. If the booster rollout had not widened existing disparities, the share of booster doses received by each race or ethnicity would have replicated those observed during the initial series. Instead, the US booster campaign widened disparities among Hispanic, $\mathrm{NH}$-Asian and $\mathrm{NH}$-Black individuals and introduced disparities among $\mathrm{NH}-\mathrm{Al} / \mathrm{AN}$ and $\mathrm{NH}-\mathrm{NHOPI}$ individuals.

Because the booster-eligible population was comprised of individuals who had received the initial series, these findings cannot simply reflect lower vaccine interest. ${ }^{5}$ Alternative explanations include decreased access to care in communities with higher rates of racial and ethnic minority individuals, a known driver of similar disparities. ${ }^{6}$ For example, mass vaccination sites and other community-based programs likely narrowed what otherwise might have been even greater disparities during the initial rollout. However, many such sites were closed during the booster rollout. Also, vulnerable populations may have had less access to booster-related public messaging and therefore been unaware both of their booster eligibility and any corresponding benefits.

While disparities in the administration of the initial series have narrowed for some groups in recent months, current policies require that either 2 months (Janssen) or 6-months (PfizerBioNTech and Moderna) must have elapsed before an individual becomes booster-eligible. This policy stands to reinforce the inequities we have described here. 
medRxiv preprint doi: https://doi.org/10.1101/2021.12.12.21267663; this version posted December 14, 2021. The copyright holder for this preprint (which was not certified by peer review) is the author/funder, who has granted medRxiv a license to display the preprint in perpetuity. It is made available under a CC-BY-NC-ND 4.0 International license .

Study limitations include data lags and incomplete reporting of race and ethnicity data.

\section{Data Statement and Author Contributions:}

Dr. Faust had full access to all of the data in the study and takes responsibility for the integrity of the data and the accuracy of the data analysis.

Concept and design: Faust, Renton, Krumholz

Acquisition, analysis, or interpretation of data: Faust, Renton, Essien, Gounder, Lin, Krumholz

Drafting of the manuscript: Faust, Essien, Krumholz

Critical revision of the manuscript for important intellectual content: Faust, Essien, Gounder, Lin,

Krumholz

Statistical plan and analysis: Faust, Lin

Administrative, technical, or material support: Renton

Supervision: Faust, Lin, Krumholz

\section{Funding Statements:}

This study had no specific funding.

\section{Conflicts of Interest:}

Faust: None.

Renton: None. 
medRxiv preprint doi: https://doi.org/10.1101/2021.12.12.21267663; this version posted December $14,2021$. The copyright holder for this preprint (which was not certified by peer review) is the author/funder, who has granted medRxiv a license to display the preprint in perpetuity.

It is made available under a CC-BY-NC-ND 4.0 International license .

Essien: Dr. Essien reported receiving grants from the Department of Veterans Affairs.

Gounder: None.

Lin: Dr Lin reported working under contract with the Centers for Medicare \& Medicaid

Services.

Krumholz: In the past three years, Dr Krumholz received expenses and/or personal fees from

UnitedHealth, IBM Watson Health, Element Science, Aetna, Facebook, the Siegfried and

Jensen Law Firm, Arnold and Porter Law Firm, Martin/Baughman Law Firm, F-Prime, and the

National Center for Cardiovascular Diseases in Beijing. He is an owner of Refactor Health and

HugoHealth, and had grants and/or contracts from the Centers for Medicare \& Medicaid

Services, Medtronic, the U.S. Food and Drug Administration, Johnson \& Johnson, and the

Shenzhen Center for Health Information.

\section{References}

1. CDC. COVID Data Tracker. Centers for Disease Control and Prevention. Published March 28, 2020. Accessed September 6, 2021. https://covid.cdc.gov/covid-data-tracker

2. KFF. COVID-19 Vaccinations by Race/Ethnicity: Differences and Limitations Across Measures. KFF. Published October 6, 2021. Accessed December 8, 2021. https://www.kff.org/racial-equity-and-health-policy/issue-brief/covid-19-vaccinationsrace-ethnicity-differences-limitations-across-measures/

3. Oliver S. Pfizer-BioNTech and Moderna COVID-19 vaccine booster doses. :68.

4. CDC/NCHS. Single-Race Population Estimates 2010-2020 by State and Single-Year Age Results Form. Accessed December 8, 2021. https://wonder.cdc.gov/controller/datarequest/D170;jsessionid=BAA4FCoC $3018 \mathrm{~EB} 0 \mathrm{~B}_{7} \mathrm{E} 6 \mathrm{E}$ B6868DA2

5. Grumbach K, Judson T, Desai M, et al. Association of Race/Ethnicity With Likeliness of COVID-19 Vaccine Uptake Among Health Workers and the General Population in the San 
medRxiv preprint doi: https://doi.org/10.1101/2021.12.12.21267663; this version posted December 14, 2021. The copyright holder for this preprint (which was not certified by peer review) is the author/funder, who has granted medRxiv a license to display the preprint in perpetuity.

It is made available under a CC-BY-NC-ND 4.0 International license .

Francisco Bay Area. JAMA Intern Med. 2021;181(7):1008-1011.

doi:10.1001/jamainternmed.2021.1445

6. Essien UR, Dusetzina SB, Gellad WF. A Policy Prescription for Reducing Health

Disparities-Achieving Pharmacoequity. JAMA. 2021;326(18):1793-1794.

doi:10.1001/jama.2021.17764

\section{Figure Title:}

COVID-19 Vaccinations by Race and Ethnicity in the United States, 2021

\section{Figure Legend:}

The gray circles indicate the share of COVID-19 vaccine-eligible US adults; the blue circles indicate the share of COVID-19 vaccine initial series doses received among the eligible US adult population for each race/ethnicity; the orange circles indicate the share of COVID-19 vaccine booster doses received among the booster-eligible US adult population for each race/ethnicity, as of November 16, 2021. In all cases, 95\% confidence intervals are synonymous with the visible centers of the corresponding circles, with no overlap between any adjacent or overlapping circles (see Table), and are therefore not shown. 
medRxiv preprint doi: https://doi.org/10.1101/2021.12.12.21267663; this version posted December 14, 2021. The copyright holder for this preprint (which was not certified by peer review) is the author/funder, who has granted medRxiv a license to display the preprint in perpetuity.

It is made available under a CC-BY-NC-ND 4.0 International license .

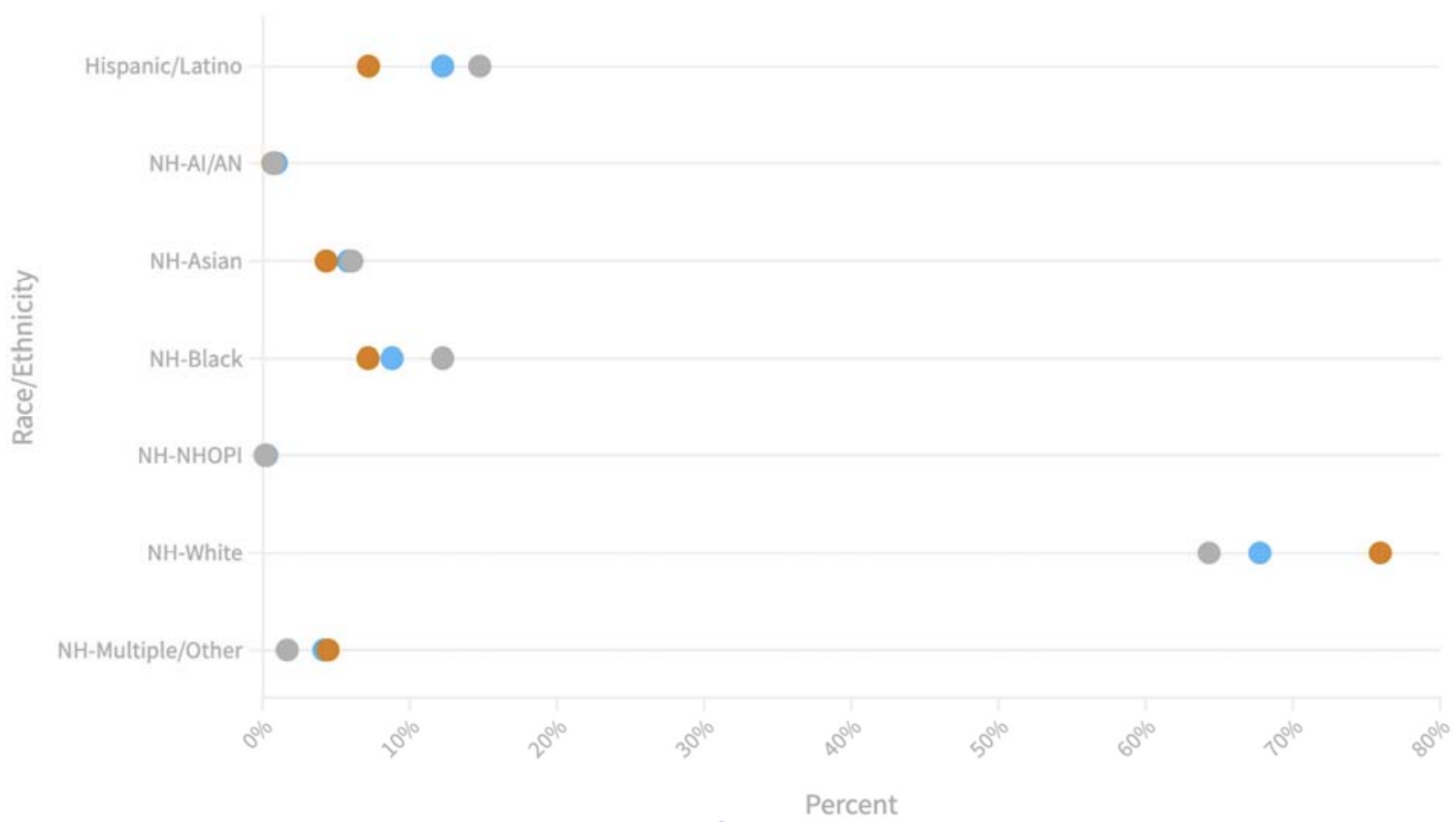

Table. COVID-19 Vaccinations and disparities by Race and Ethnicity for the initial series and booster in the United States, 2021

\begin{tabular}{|c|c|c|c|c|c|c|}
\hline Race/ethnicity & Adult population & Share of adult population & Vaccinated adults (initial series) $^{*}$ & Share of initial doses received ${ }^{*}$ & Absolute disparity** & Chi-square p-val \\
\hline Total (with known race and ethnicity) & $234,736,383$ & & $85,806,925$ & & & \multirow[t]{8}{*}{$<0.001$} \\
\hline Hispanic/Latino & $34,643,869$ & $14.76 \%(95 \% \mathrm{Cl} 14.75 \%-14.76 \%)$ & $10,505,659$ & $12.24 \%(95 \% \mathrm{Cl} 12.24 \%-12.25 \%)$ & $-2.52 \%$ & \\
\hline Non-Hispanic Al/AN ${ }^{* * * *}$ & $1,759,908$ & $0.75 \%(95 \% \mathrm{Cl} 0.75 \%-0.75 \%)$ & 797,976 & $0.93 \%(95 \% \mathrm{Cl} 0.93 \%-0.93 \%)$ & $0.18 \%$ & \\
\hline Non-Hispanic Asian & $14,255,119$ & $6.07 \%(95 \% \mathrm{Cl} 6.07 \%-6.08 \%)$ & $5,004,914$ & $5.83 \%(95 \% \mathrm{Cl} 5.83 \%-5.84 \%)$ & $-0.24 \%$ & \\
\hline Non-Hispanic Black & $28,734,901$ & $12.24 \%(95 \% \mathrm{Cl} 12.24 \%-12.25 \%)$ & $7,547,654$ & $8.80 \%(95 \% \mathrm{Cl} 8.79 \%-8.80 \%)$ & $-3.44 \%$ & \\
\hline Non-Hispanic NHOPI"**** & 437,957 & $0.19 \%(95 \% \mathrm{Cl} 0.19 \%-0.19 \%)$ & 231,614 & $0.27 \%(95 \% \mathrm{Cl} 0.27 \%-0.27 \%)$ & $0.08 \%$ & \\
\hline Non-Hispanic White & $150,959,164$ & $64.31 \%(95 \% \mathrm{Cl} 64.30 \%-64.32 \%)$ & $58,138,817$ & $67.76 \%(95 \% \mathrm{Cl} 67.75 \%-67.77 \%)$ & $3.45 \%$ & \\
\hline Non-Hispanic Multiple/Other & $3,945,465$ & $1.68 \%(95 \% \mathrm{Cl} 1.68 \%-1.68 \%)$ & $3,580,291$ & $4.17 \%(95 \% \mathrm{Cl} 4.17 \%-4.18 \%)$ & $2.49 \%$ & \\
\hline Race/ethnicity & Booster-eligible adult population & Share of booster-eligible population & Vaccinated adults (booster dose) ${ }^{\star \star \star \star}$ & Share of booster doses received ${ }^{\star \star \star}$ & Absolute disparity** & Chi-square p-val \\
\hline Total (with known race and ethnicity) & $85,806,925$ & & $18,832,653$ & & & \multirow[t]{8}{*}{$<0.001$} \\
\hline Hispanic/Latino & $10,505,659$ & $12.24 \%(95 \% \mathrm{Cl} 12.24 \%-12.25 \%)$ & $1,355,230$ & $7.20 \%(95 \% \mathrm{Cl} 7.18 \%-7.21 \%)$ & $-5.04 \%$ & \\
\hline Non-Hispanic Al/AN"**** & 797,976 & $0.93 \%(95 \% \mathrm{Cl} 0.93 \%-0.93 \%)$ & 134,060 & $0.71 \%(95 \% \mathrm{Cl} 0.71 \%-0.72 \%)$ & $-0.22 \%$ & \\
\hline Non-Hispanic Asian & $5,004,914$ & $5.83 \%(95 \% \mathrm{Cl} 5.83 \%-5.84 \%)$ & 815,801 & $4.33 \%(95 \% \mathrm{Cl} 4.32 \%-4.34 \%)$ & $-1.50 \%$ & \\
\hline Non-Hispanic Black & $7,547,654$ & $8.80 \%(95 \% \mathrm{Cl} 8.79 \%-8.80 \%)$ & $1,351,030$ & $7.17 \%(95 \% \mathrm{Cl} 7.16 \%-7.19 \%)$ & $-1.63 \%$ & \\
\hline Non-Hispanic NHOPI $\left.\right|^{\ldots \ldots * * *}$ & 231,614 & $0.27 \%(95 \% \mathrm{Cl} 0.27 \%-0.27 \%)$ & 36,595 & $0.19 \%(95 \% \mathrm{Cl} 0.19 \%-0.20 \%)$ & $-0.08 \%$ & \\
\hline Non-Hispanic White & $58,138,817$ & $67.76 \%(95 \% \mathrm{Cl} 67.75 \%-67.77 \%)$ & $14,302,149$ & $75.94 \%(95 \% \mathrm{Cl} 75.92 \%-75.96 \%)$ & $8.18 \%$ & \\
\hline Non-Hispanic Multiple/Other & $3,580,291$ & $4.17 \%(95 \% \mathrm{Cl} 4.17 \%-4.18 \%)$ & 837,788 & $4.45 \%(95 \% \mathrm{Cl} 4.44 \%-4.46 \%)$ & $0.28 \%$ & \\
\hline \multicolumn{7}{|c|}{ As of May 16, 2021 for Pfizer-BioNtech or Moderna, of September 16, 2021 for Janssen } \\
\hline \multicolumn{7}{|l|}{$\begin{array}{l}\text { "Negative values indicate a lor } \\
\cdots \text { As of November } 16,2021 \\
\end{array}$} \\
\hline
\end{tabular}

